\title{
Teacher Relational Competence and Behavior Management Implementation
}

\author{
Rachel Bringewatt, M. Ed \\ Meredith L. P. Bram, M.Ed. \\ Ebonee Henry, BA \\ School of Professional and Continuing Studies \\ 421 Westhampton Way \\ University of Richmond, VA 23173 \\ University of Richmond \\ Erik K. Laursen, Ph.D. \\ Adjunct Professor \\ School of Professional and Continuing Studies \\ 421 Westhampton Way \\ University of Richmond, VA 23173
}

\begin{abstract}
In order to respond productively to student disruptions, teachers must have the skills and awareness to connect with students responsively rather than reactively. Practices grounded in relationships such as social emotional learning, mindfulness, restorative, and trauma-informed practices have been shown to improve student academic engagement and behavior. They are becoming more widely known and encouraged in schools. This mixed methods study gathered data from first through third grade teachers on their relational competence and their most used behavior management practices. While survey data did not show a correlation between high teacher relational competence and usage of relationship-building practices, in-depth interviews suggested that a connection may exist.
\end{abstract}

Keywords: relational competence, class leadership, behavior management, social emotional learning, mindfulness, restorative practices, trauma-informed practices

\section{Introduction}

As teachers we strive to create a positive culture in our classroom with high expectations supported by meaningful student-teacher and peer relationships. We envision our classrooms as places where each child feels connected, valued, and inspired to learn as a curious student and a caring citizen.

However, in real life, children's actions can at times jeopardize classroom community and continuity of learning. Teachers are challenged to balance learning and emotional growth, while upholding the values of a classroom community and managing student disruptions. We have observed that responses to students, who do not follow class expectations, are often grounded in reward-consequence practices. We have participated in pre-service and in-service trainings in social emotional learning (SEL), mindfulness, restorative, and trauma-informed practices and have experienced some friction between these and the traditional reward-consequence management system.

We use the term relationship-building practices to refer to social emotional learning (SEL), mindfulness, restorative, and trauma-informed practices. In our experience, teachers are encouraged to use such practices, but they are not always promoted as a behavior management approach. We believe relationship-building practices can be utilized as an encompassing framework for class leadership that includes both community building and behavior management. To implement relationship-building practices in this way, it is essential that teachers can establish and maintain relationships with their students. We refer to this skill as relational competence.

\subsection{Background}

The influence of teacher-student and peer relationships on children's academic and social emotional growth is a critical topic to understand for this study. Research shows that relationship-building practices, such as SEL, mindfulness, restorative, and trauma-informed practices, improve student well-being and behavior (e.g., Hattie, 2009; Jennings \& Greenberg, 2009; Jones et al., 2013). 
Despite this, these practices are not referred to in existing literature as behavior management approaches. We seek to reframe these practices as an approach to class leadership, including community building and behavior management and to explore if teachers' relational competence influences their usage of relationship-building practices and their responses to student disruptions.

\subsection{Benefits of Positive Classroom Relationships}

Education is a complex human venture, and quality academic instruction is just one part of a functioning classroom. It is not enough that teachers know the subjects they teach, they must also know and reflect on the relations that exist within their classrooms. Teacher-student and student-student relations are essential when building a community of learners. Effective teachers utilize excellent pedagogical strategies, while simultaneously providing emotional support to students through positive relationships. Positive teacher-student relationships have been linked toprosocial student behavior and greater academic engagement (Roorda et al., 2011).Jennings and Greenberg (2009) found that students, who had kind and communicative teachers, felt emotionally secure, self-confident, and devoted more attention to and increased learning.

Peer relationships are just as valuable. In classroom communities where a greater number of students felt socially connected, engagement was higher due to minimized classroom disruptions. When students felt supported by and had friendly relationships with their classmates, students exhibited more on-task behavior (Capella et al., 2013). Positive teacher-student and peer relations were also found to contribute to increased participation in learning and a stronger sense of accountability to the class community. Conversely, in the absence of this, student academic performance and engagement suffered (Rucinski et al., 2017).

Despite the importance of positive and supportive relations emphasized in the literature, only a few studies in the United States have focused on understanding or developing teachers' capacities for building positive relationships. Research has shown that teachers social and emotional competence is an influential factor in developing classroom relationships (Jennings \& Greenberg, 2009). However, there is little supporting research focused on teacher outcomes or ways in which teachers' connection-building skills could be strengthened. Teachers' personal characteristics influenced their attitudes towards students which was reflected in their ability to provide a safe and psychologically secure classroom (Harvey et al., 2012). Teachers with higher emotional intelligence were more aware and better able to regulate their own emotions. In turn, they were able to intentionally respond to the root of student behavior rather than react to student actions (Valente et al., 2018). Similarly, teachers with higher emotional intelligence had higher selfefficacy, which had a positive effect on teacher performance (Wu et al., 2019).

\subsection{Teacher Relational Competence}

Relational competence is a concept that originated in Scandinavia (e.g., Aspelin\& Johnson, 2019, Juul \& Jensen, 2002). Strong teacher-student relationships require the teacher to show respect, tolerance, empathy, and interest in students (Jensen et al., 2015). To this end, relational competence embodies three different concepts: a teacher's ability to see a student for who they truly are beyond any negative behavior; a teacher's sense of ownership or leadership of educational processes; and a teacher's sense of responsibility for the teacher-student relationship. This includes the responsibilities to act authentically, have respect for, and exhibit empathy towards all students (Juul\& Jensen, 2002, as cited in Jensen et al., 2015). Teachers must understand the underlying reason for student disruptions and noncompliance with classroom expectations. Teachers must also lead instruction in a way that makes a student feel safe and included (Jensen et al., 2015). Additionally, "a good relationship between teacher and student requires the teacher to show respect, tolerance, empathy, and interest in students" (Nordenbo et al., 2008, as cited in Laursen \& Nielsen, 2016, p. 140).

Between 2012 and 2016, a research and development project in relational competence was conducted at VIA University in Denmark (Børns Livskundskab, 2020; Jensen \& Gøtzsche, 2020; Nielsen, 2020). Student teacher participation in the relational competence project led to meaningful reflection about their classroom experiences. While there was no significant relationship found between the program and improved teacher relational competence, researchers believed that it was a step in this direction. Student teachers were able to establish stronger relationships with students (Laursen \& Nielsen, 2016).

\subsection{Relationship-Building Classroom Practices}

Given that relationships are essential to learning, significant research has been done on practices that improve relationships in the classroom. These include SEL, mindfulness, restorative, and trauma-informed practices. 


\subsection{Social Emotional Learning}

SEL is defined by the Collaborative for Academic, Social, and Emotional Learning (CASEL) as "the process through which children and adults understand and manage emotions, set and achieve positive goals, feel and show empathy for others, establish and maintain positive relationships, and make responsible decisions" (2019). According to Dunham (2019), CASEL laid the foundation for SEL programming in schools. CASEL's framework is composed of five core competencies: self-awareness, self-management, social awareness, relationship skills, and responsible decision making. SEL is a process that teaches students and adults ways to navigate and manage their emotions. It goes beyond traditional academics and focuses on the individual and their relationships with others. SEL teaches adults and children to maintain positive relationships, respect one another, and feel and show empathy towards others (CASEL, 2019).

Numerous SEL curriculums have been adopted by educators. A SEL curriculum has the goal of holistic teaching that includes crucial life skills that students will need beyond their school years. Effectiveness has varied, and researchers have found that implementation impacted the outcome (Elias et al., 2003). Implementation factors included adherence to curriculum, engagement, generalization, and dosage (Low et al., 2016). All of these may influence student outcomes as SEL participants.

Research suggests that any amount of exposure to SEL instruction benefits teachers and students. Teachers who were comfortable using SEL and perceived themselves as highly emotionally intelligent, typically developed more positive relationships with students (Poulou, 2016). Even student participants who received instruction that only met some of the implementation guidelines increased social and emotional skills, behavior, attitude, and academic performance (Durlak et al., 2011). SEL programs have also increased positive behaviors and decreased misconduct, regardless of socioeconomic class or race (Duncan et al., 2017).

\subsection{Mindfulness}

Mindfulness is described as "a process of openly attending, with awareness, to one's experience in the present moment" (Creswell, 2017, p. 492). When practiced consistently, mindfulness can prevent mind-wandering and apathy for the current situation. Mindfulness is rooted in Buddhism, psychology, and philosophy, but has made its way into educational as a strategy to introduce awareness of present moments throughout the school day. Students need to be provided with the tools to stay focused, regulate their emotions, deal with feelings of frustration, and become selfmotivated in the classroom (Zenner et al., 2014).

Mindfulness practices have had positive social emotional and cognitive effects on students (Chiesa \&Serretti, 2009). While the intention of mindfulness practices is not to control student behavior or force calm through compliance, research has suggested that one effect of a consistent mindfulness practice is improvements in student behavior. One study found that students practicing mindfulness in schools consistently had fewer behavior infractions (Barnes et al., 2003). Practicing mindfulness increased student attention span and performance on certain tasks (Semple et al., 2010), decreased emotional reactivity (Goldin \& Gross, 2010), and improved ability to handle stress and anxiety (Chiesa \&Serretti, 2009).

Mindfulness is associated with effective regulation of emotions. After six weeks of mindfulness practice, class participation, compassion for others, self-control, and attention improved (Fernando, 2013). Mindfulness creates changes in the brain that correspond to less reactivity in a high-stress situation and improvement in the ability to engage in tasks even when negative emotions are activated (Goldin \& Gross, 2010). Mindfulness also fuels a greater sense of self-compassion which translates to more peaceful interactions between people (Birnie et al., 2010). These are related to students' capacity to self-regulate in stressful situations and make positive behavior choices that increase academic performance and social emotional skills.

Academic success is more likely in a non-disruptive classroom environment. Minimal disruptions allow students to give their full attention to the teacher and the curriculum. When teachers encounter classrooms with little disruption, they are more likely to implement proactive strategies that lead to better classroom management and student learning outcomes. Implementing strategies that support prosocial behaviors such as a mindfulness program, may alleviate some of the stress of managing student behavior and improve student learning (Black \& Fernando, 2013).

\subsection{Restorative Practices}

Restorative practices stem from restorative justice. Restorative justice focuses on personal growth as opposed to compliance (Kehoe et al., 2017). In schools, students are not only learning formal academic subjects, but how to interact with others. 
They develop the skills to communicate with their peers, work with various groups of people, and learn effective problem solving. All of these require social and emotional competence. When used in schools, restorative practices holistically address student misbehavior with the aim of teaching social and emotional skills (Kehoe et al., 2017).

Restorative practices are relationship-based and support students in making amends for perceived errors in behavior. It requires teachers to guide students through a lens of appreciative inquiry, which is defined as:

a habitual stance of respectful curiosity as opposed to making assumptions and thinking that our own interpretation or meaning is the right one. It requires a patient and persistent exploration of the meanings that others make of the same event, and it requires attention to the effects of different ways of speaking (Drewery\& Kesckskemeti, 2010, p. 105).

Many schools have found that that restorative practices have positive influences on the school climate and culture. After teachers and students learned about restorative practices, they experienced an increase in social skills, including harmony, empathy, awareness, accountability, respect, thinking in reflective ways, and improved personal relationships (Kehoe et al., 2017).

Restorative practices are gaining credibility in schools (Silverman \&Mee, 2018). The use of restorative practices come from teachers' desires to build positive classroom environments as well as relationships. Restorative practices resulted in teachers feeling that they had stronger relationships with students. They used less punitive, exclusionary consequences in response to student misbehavior (Rainbolt et al., 2019). According to Wachtel (2016), restorative practices can occur on an informal to formal continuum. Informal practices include statements and conversations, whereas formal practices include circles and conferences. Restorative talking circles have led to improved listening, anger management, and self-efficacy amongst student participants (Schumacher, 2014). Additionally, schools that implemented restorative practices lowered suspension rates and improved teachers' outlooks on school climate and culture (Augustine et al., 2018).

\subsection{Trauma-informed Practices}

While multiple definitions exist, childhood trauma can be defined as "a response to a negative external event or series of events which surpasses the child's ordinary coping skills" (McInerney\&McKlindon, 2014, p. 1). More than two thirds of children experience some form of trauma (Substance Abuse and Mental Health Services Administration, 2017). Growing research on the detrimental impacts of childhood trauma on brain development, behavior, and academic performance has led educators to realize the relevancy of trauma-informed practices (Shonk\& Cicchetti, 2001).

Trauma-informed care is defined as "a way of approaching interactions with children and families in which providers remain cognizant of the impacts of trauma while also taking actions to prevent potentially traumatic experiences" (Boles, 2017, p. 251). While this is common in the medical sphere, creation of trauma-informed schools is new and evolving (Perry \& Daniels, 2016). Trauma-informed best practices include creating safe space, assisting students in nervous system regulation, building connected relationships, supporting the development of a coherent narrative, empowering students, building social emotional and resiliency skills, and fostering post-traumatic growth (Echo, 2017). Supporting students with trauma involves intentional relationship-building and a shift in mindset to focusing on what is strong, not what is wrong with children (Laursen, 2018).

Implementation of a school-wide trauma prevention and intervention programled to decreased office referrals, physical aggressions, and suspension rates(Dorado et al., 2016). Students, who participated in the program reported increased self-regulation, ability to managetheir emotions, and connecting with others. Similarly, teachers who used traumainformed strategies with preschool students reported increased confidence about classroom management and lower use of reward-consequence interventions. They also reported that student resilience improved (Shamblin et al., 2017).

\subsection{Summary}

The existing literature supports the idea that teacher-student and peer relations are integral to instruction and student learning. It is also evident that relationship-building practices, including SEL, mindfulness, restorative, and traumainformed practices, have a positive impact on student learning and behavior. Therefore, we believe that these practices can be used as an overarching approach to class leadership that encompasses community building and behavior management. Our study was grounded in this notion and explored the connection between teacher relational competence and their usage of relationship-building practices as well as their responses to student disruptions. 


\subsection{Design}

The sequential explanatory design (Creswell \& Clark, 2018) was a good fit for our study because it allowed us first to survey participants about their level of relational competence and their usage relationship-building practice. Based on the analysis of these responses, we developed behavior management scenarios to explore how teachers who reported using a high percentage of relationship-building practices responded to student disruptions and non-compliance with classroom expectations. The aim of the study was to learn if teachers with high relational competence were more likely to utilize relationship-building practices in these situations.

\subsection{Research Team}

The research team consisted of three elementary teachers and their university professor and was part of a required graduate course. Two of the teachers were first year teachers, and the third had two years' experience. The topic was established based on the teachers' interest and the professor brought the relational competence construct to the teachers' attention and consulted with them throughout the process.

\subsection{Setting and Participants}

The data were collected at a Title I school in Virginia that served 613 students in the 2019-2020 school year. The school was in the second year of using the SEL curriculum Caring School Community (Center for the Collaborative Classroom, 2020).

Fourteen first through third grade teachers were invited via email to complete a survey and 12 responses were received. The five teachers who reported the highest percentage use of relationship-building practices were invited to participate in one-one in-depth interviews.

\subsection{Methods}

Prior to completing the survey and interview participation, consent forms were provided and signed. Participants were presented with a list of 31 management practices, ranging from reward-consequence to relationship-building, and asked to select the practices they used on a consistent basis in their classrooms. The survey also included 33 questions that assessed relational competence developed by Vidmar and Kerman (2016). These questions used a Likert scale to evaluate overall teacher relational competence in three areas: respect for individuality, authenticity, and responsibility for relationship.

Following analysis of the surveys, four of five teachers, who had reported a high usage of relationship-building practices, agreed to be interviewed. These interviews were conducted and recorded via Zoom video calls.

\subsection{Data Analysis}

\subsection{Teacher Relational Competence Survey Results}

Participants' total relational competence scores ranged from 104 to 134 points. Three participants ranked in the competent stage (Vidmar \& Kerman, 2016), and the other nine participants ranked in the advanced stage. The average relational competence score of 121 points fell in the advanced category. Scores in the relational competence component categories of respect for authenticity, respect for individuality, and responsibility for relationship also varied by teacher. These results are shown in Table 1.

Table 1 Average Teacher Relational Competence

\begin{tabular}{lll}
\hline & Average Score & Average Stage \\
\hline Total Relational Competence & 121 & Advanced \\
Authenticity & 37 & Competent \\
Respect for Individuality & 38 & Expert \\
Responsibility for Relationship & 46 & Advanced \\
\hline
\end{tabular}

Survey results showed that all participants utilize both relationship-building and reward-consequence practices. On average, $64 \%$ of teachers' self-reported practices were relationship based and $46 \%$ were reward-consequence based. Linear regressions were used to determine if teacher relational competence scores were correlated with the number or the percentage of relationship-building practices. 
As shown in Figure 1 and Figure 2, the data visually suggests a connection. However, there is no statistical significance based on the $\mathrm{R}^{2}$ values of .4027 (Figure 1) and .3533 (Figure 2). The small sample size is a limitation and to conclusively determine correlation more data is needed.

Figure 1 Correlation Between Relational Competence and Number of Relationship-Building Practices

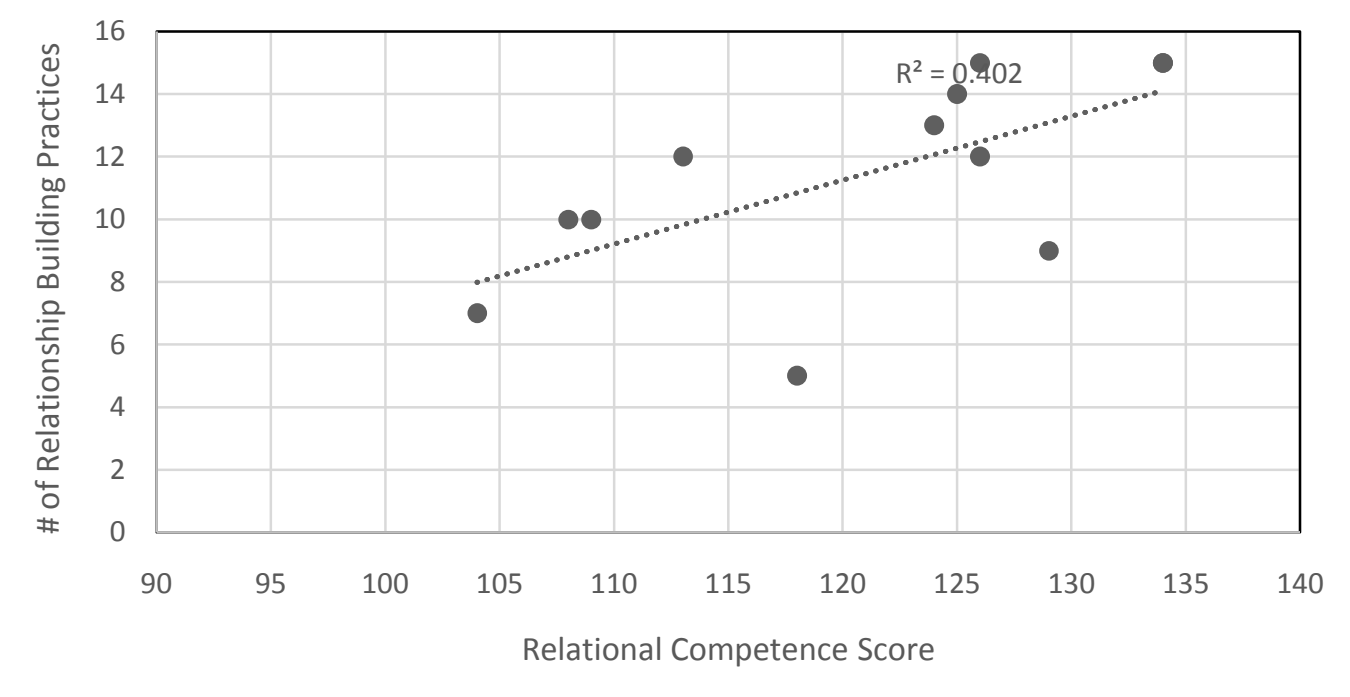

Figure 2 Correlation Between Relational Competence and Percentage of Relationship-Building Practices

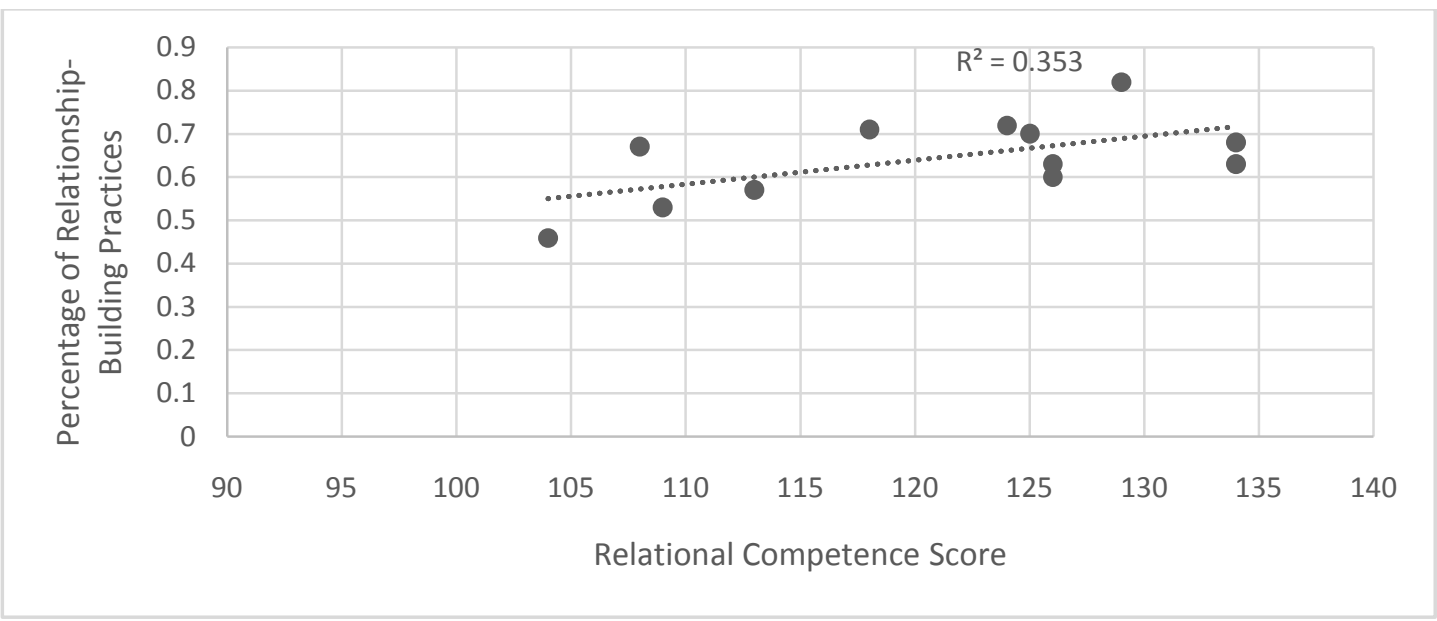

\subsection{Teacher Interview Results}

While the survey results did not show a statistically significant relation between teachers' usage of relationshipbuilding practices and their relational competence score, we conducted four in-depth interviews to further explore this dynamic and to understand if teachers' relational competence influenced how and if they used such practices in response to student disruptions.

Interview participants were presented with five classroom scenarios in which a student did not follow classroom expectations or was disruptive and asked to describe how they would respond to each situation. The interviews were transcribed using Trint software and coded to determine key phrases and themes. Using inductive analysis (Liu, 2016), the codes were used to further categorize the data and understand if teachers' behavior management practices were related to their relational competence score, i.e., were teachers with high relational competence scores more likely to select relationship-building practices over rewards and consequences. Table 2 shows data associated with each interview participant. 
Table 2 Teacher Interview Participants

\begin{tabular}{ccccc}
\hline Teacher & $\begin{array}{c}\text { Relational } \\
\text { Competence }\end{array}$ & $\begin{array}{c}\text { Reward-Consequence } \\
\text { Practices }\end{array}$ & $\begin{array}{c}\text { Relationship Building } \\
\text { Practices }\end{array}$ & $\begin{array}{c}\text { Percentage Relationship } \\
\text { Building Practices }\end{array}$ \\
\hline 8 & 118 & 2 & 5 & $71 \%$ \\
9 & 124 & 5 & 13 & $72 \%$ \\
10 & 125 & 8 & 14 & $70 \%$ \\
6 & 134 & 7 & 15 & $68 \%$ \\
\hline
\end{tabular}

Analysis of the interviews identified that the teachers used relationship-building practices to either primarily foster community within their classrooms or to foster community and as a behavior management approach.

\subsection{Findings}

\subsection{Relationship-building Practices to Foster Community}

Teacher eight built relationships with her students because she preferred not to be viewed as a "distant authority figure." She focused on establishing mutual respect and getting to know students' personalities, "They know that I'm their teacher and that respect is necessary, but they do not take me too seriously. I think it makes them more comfortable." This year she started using a SEL curriculum in her classroom and felt that it has helped her focus on the "whole child." She has also noticed a positive difference in peer interactions. In response to questions about her actions related to behavior management she reported using Class Dojo points, praising positive behavior, redirecting with alternate tasks, and using proximity with students. Such approaches are anchored in the traditional system of rewards and consequences.

Teacher ten also focused on building classroom relationships through SEL. "I always like starting off with our morning meetings. I try to be really personal with my students." For this teacher, the SEL curriculum was separate from her responses to class or behavior misbehavior. For example, she told students exhibiting poor behavior, "that is not, okay," and redirected or corrected a student in front of the whole class. In situations where a student was disruptive, she would "ask them to move to the desk that is right next to me .I would tell them that this is not a negative thing, but this is a safe space where you can work, where you are not distracting others, and you are not getting is tracted yourself."'Other practices in her repertoire included a clip up, clip down system, and rewarding students meeting her expectations, e.g., lunch with her or invitation to a homework club.

In summary, while these two teachers used relationship-building practices in their classroom for community building purposes, their behavior management approach may be more centered on a reward-consequence system.

\subsection{Relationship-building Practices as a Class Leadership Approach}

Teacher nine saw relationships as the foundation of an interconnected community of students, teachers, and parents, and supported students in understanding that "community goes back to understanding that we are all different, and to embrace and celebrate diversity and just ultimately be respectful and treat each other with kindness." She implemented SEL through morning meetings and class problem solving. Additionally, she had a calm-down corner in her classroom where students are taught to use mindfulness strategies such as deep breathing. When responding to students who did not follow classroom expectation, she often relied on relationship-building practices, e.g., "I would not want to disrupt their learning too much. I would not want to put the student on the spot. I would redirect her in the best way that I could and positively state what I wanted her to do." She explained she would let students breathe and reset before conversing with them in a small group by stating "I understand you are trying to help, but this is a problem that I will work on. I will solve this problem with him."

Her initial response was grounded in relationship-building practices, but she appeared to also use reward-consequence practices in her communication with students. She took ownership of the final resolution of the problem as the authority figure rather than collaboratively problem solving with students.

Teacher six had the highest total relational competence score of all interview participants. Her philosophy was grounded in relationships, which was manifested in all aspects of her practice. She explained that she treats her classroom as family from day one and advocated for educating the whole child. She was the only teacher who consistently used the language and strategies embedded in 
SEL, mindfulness, restorative, and trauma-informed practices in her classroom as behavior management approach while responding to the behavioral scenarios in the interview.

Classroom meetings are used for both community building and responding to student disruptions. These meetings allow for proactive relationship-building but also collaborative problem solving. "It creates a safe space where they feel that if they have a problem, they can bring it in front of the class, and no one will judge them. The whole class will help in problem solving and brainstorming." Additionally, she recognized that there are often underlying causes of behavior and saw value in talking to students about their thoughts and feelings. She shared her thoughts about understanding student experiences.

I don't have the right words and the ability to communicate how they're feeling or why they're feeling that way, and especially with ... students (who have experienced trauma). You can sometimes know the kid has experienced trauma, but sometimes you don't. It shows in different ways. So, I always have tended to be mindful of how I react to a situation because I never know why they are reacting that way.

Having intentional conversations was central to her responses to each behavior management scenario. She explained she would acknowledge student feelings through one-on-one conversations, encourage mindful breathing, and facilitate class meetings. She did note that she sometimes supplements with more traditional reward-consequence practices. She has found a class economy system such as Class Dojo, classroom dollars, or tickets to be effective for some classes in the past.

In summary, teacher six and nine used relationship-building practices as their overarching approach to class leadership, including fostering community and managing behavior. While the two teachers primarily used SEL, mindfulness, restorative, and trauma-informed practices to develop positive classroom cultures and reduce disruptions, they also at times use consequences and rewards.

\section{Conclusion}

Our inquiry did not answer the question, are teachers with higher relational competence more likely to use relationshipbuilding practices in their classroom in response to student misbehavior, affirmatively. However, it appears that teachers' relational competence influence how teachers utilize relationship-building practices in their classrooms ranging from primarily community building to a comprehensive classroom leadership approach encompassing both community building and behavior management. Figure 3 shows interviewed teachers plotted on this continuum.

Figure 3 Relationship-Building Practice Usage Continuum

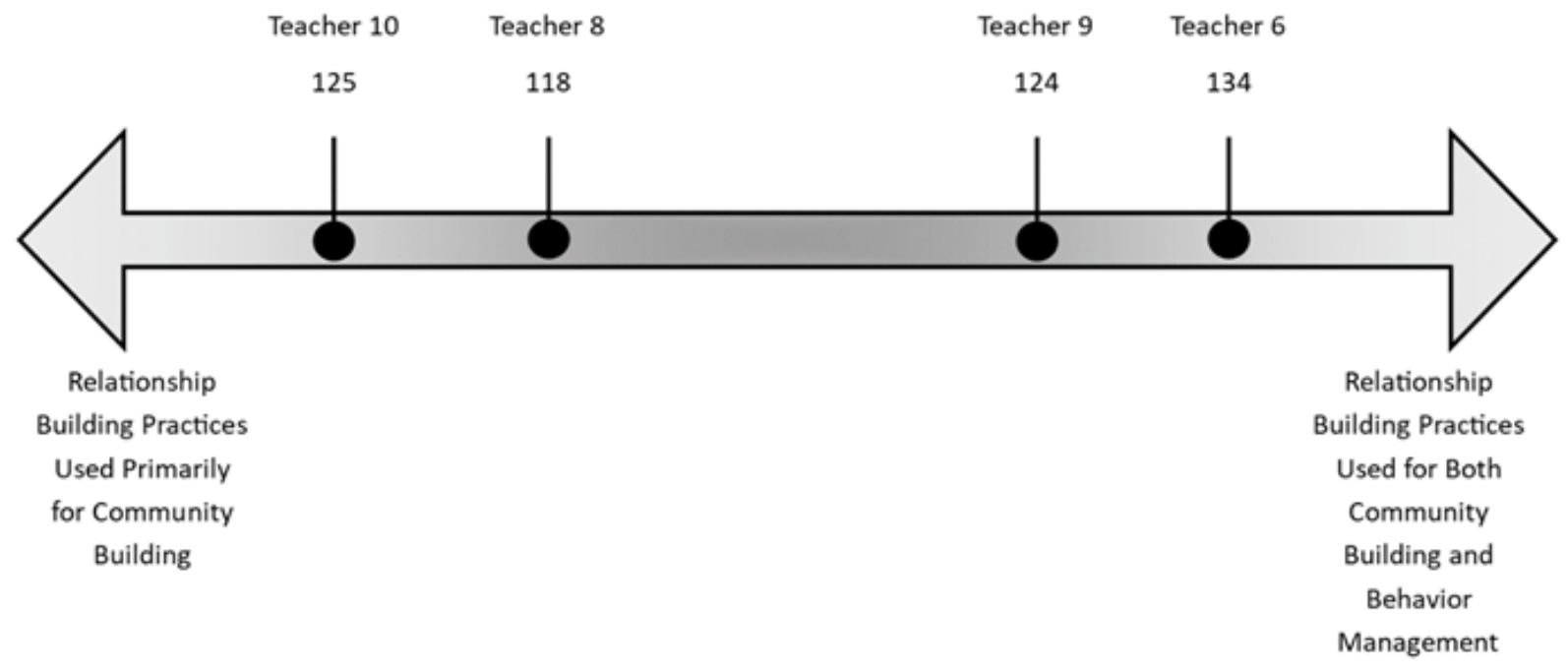

On the continuum, teacher six had the highest relational competence and viewed SEL, mindfulness, restorative, and trauma-informed practices as an overarching approach to class leadership including community building and behavior management. Her responses to student behavior scenarios showed a high level of intentionality and finesse when responding to student disruptions. The other three teachers sometimes used relationship-building practices with students who did not follow classroom expectations. 
Regardless of their relational competence score, all teachers emphasized the importance of setting norms and expectations and establishing relationships to maximize student learning.

Currently, behavior management and relationship-building are often disconnected in the classroom. SEL, mindfulness, restorative, and trauma-informed practices are presented to teachers as silos rather than as related classroom leadership tools that can be utilized for both community-building and behavior management. Relationship-building practices can create community while maximizing student engagement and minimizing disruptions. They have the potential to be a powerful framework to create an effective learning environment where all students can thrive.

To successfully implement relationship-building practices in this manner, pre- and in-service teachers should be provided training that allows for practice, growth, and reflection on their relational competence. While not automatically transferable to the US, such initiatives have already been taken in Europe (e.g., Kozina, 2020, Jensen et al., 2015). Additionally, more data should be collected from a larger teacher population to determine if a statistically significant correlation exists between teacher relational competence and relationship-building practice usage. Our hope is that such efforts will encourage educators to grow their practice and feel supported in responding to student behavior with connection, intentionality, and reflection.

\section{References}

Aspelin, J. (2017). In the heard of teaching: A two-dimensional conception of teachers' relational competence. Education Practice and Theory, 39(2), 39-56.

Aspelin, J. \& Jonsson, A. (2019). Relational competence in teacher education: Concept analysis and report from a pilot study. Teacher Development, 23(2), 264-283.

Augustine, C. H., Engberg, J., Grimm, G. E., Lee, E., Wang, E. L., \& Christianson, K. (2018).Can restorative practices improve school climate and curb suspensions? An evaluation of the impact of restorative practices in a midsized urban school district. RAND Corporation.https://doi.org/10.7249/RR2840

Barnes,V.A.,Bauza,L.B.,\&Treiber,F.A.(2003).Impactofstressreductiononnegative school behavior in adolescents. Health and Quality of Life Outcomes, 7(1), 1-10. https://doi.org/10.1186/1477-7525-1-10

Birnie,K.,Speca,M.,\&Carlson,L.E(2010).Exploringself-compassionandempathyinthe contextofmindfulnessbasedstressreduction(MBSR).StressandHealth,26(5),359- 371.https://doi.org10.1002/smi.1305

Black, D., \& Fernando, R. (2014). Mindfulness training and classroom behavior among lowerincomeandethnicminorityelementaryschoolchildren.JournalofChild\& Family Studies, 23(7), 1242-1246. https://doi-org.newman.richmond.edu/10.1007/s10826-013-9784-4

Boles,J.(2017).Trauma-informedcare:Anintentionalapproach.PediatricNursing,43(5), 250-255. https://searchebscohost-com.newman.richmond.edu/login.aspx?direct $=$ true \&db=ehh\&AN=125833581\&site=ehost-live

BørnsLivskundskab. (2020, July 22). Empathy ognærvær i folkeskolen: En film omrelationskompetence[Empathy and presence: A film about relational competence in the public schools.

https://www.youtube.com/watch?v=Vg1fKkwKJyo

Cappella,E.,Kim,H.Y.,Neal,J.W.,\&Jackson,D.R.(2013).Classroompeerrelationships and behavioral engagement in elementary school: The role of social networkequity.AmericanJournalofCommunityPsychology,52(3),367379.https://doi.org/10.1007/ S10464-013-9603-5

Center for the Collaborative Classroom.(2020).Caring school community. Principles and structures to develop social skills.https://www.collaborativeclassroom.org/programs/caring-school-community/

Chiesa,A.,\&Serretti,A.(2009).Mindfulness-basedstressreductionforstressmanagementin healthy people: A review and meta-analysis. The Journal ofAlternative and Complementary Medicine, 15(5), 593-600. https://doi.org/10.1089/acm.2008.0495

Collaborative for Academic, Social, and Emotional Learning (CASEL) (2019). What is SEL? https://casel.org/what-is-sel/

Creswell,J.D.(2017).Mindfulnessinterventions. Annual Review of Psychology, 68(1),491-516. https://doi:10.1146/annurev-psych-042716-051139

Creswell, J. C. \& Clark, V. L. P. (2018). Designing and conducting mixed methods research ( ${ }^{\text {rd }}$ ed.). Thousand Oaks, CA: Sage.

Dorado,J.S.,Martinez,M.,McArthur,L.E.,\&Leibovitz,T.(2016).Healthyenvironmentsand response to trauma in schools (HEARTS): A whole-school, multi-level prevention and intervention program for creating traumainformed,safe, and supportive chools. School Mental Health, 8(1),163-176. https://doi.org/10.1007/s12310-016-9177-0

Drewery,W.,\&Kecskemeti,M.(2010).Restorativepracticeandbehaviourmanagementin schools: Discipline meets care. Waikato Journal ofEducation, 15(3), 101-113. https://doi.org/10.15663/wje.v15i3.85 
Duncan, R., Washburn, I. J., Lewis, K. M., Bavarian, N., Du Bois, D. L., Acock, A. C., Vuchinich,S.,\&Flay,B.R.(2017).Canuniversal SEL programs benefit universally? Effects of the positive action program on multiple trajectories of social-emotional and misconduct behaviors. Prevention Science, 18(2), 214-224. https://doi.org/ 10.1007/s11121-016-0745-1

Dunham,M.(2019).The missing piece. A history of SEL in schools. Aperture Education. https://apertureed.com/missing-piece-history-sel-schools/

Durlak,J.A.,Dymnicki,A.B.,Taylor,R.D.,Weissberg,R.P.,\&Schellinger,K.B.(2011).The impact of enhancing students' social and emotional learning: A meta-analysis of school-based universal interventions. Child Development,82(1),405-432. https://doi.org/10.1111/j.1467-8624.2010.01564.x

Echo. (2017). Trauma resources. https://www.echotraining.org/infographics/

Elias, M. J., Zins, J. E., Graczyk, P. A., \& Weissberg, R. P. (2003). Implementation, sustainability, and scaling up of social-emotional and academic innovations in public schools. School Psychology Review, 32(3), 303319.https://www.tandfonline.com/doi/abs10.1080/02796015.2003.12086200

Fernando,R.(2013).Measuring the efficacy and sustainability of mindfulness-based in-class intervention. Mindful Schools. https://www.mindfu1schools.org/wp-content/up1oads/2019/10/Mindful-Schools-Study-Highlights.pdf

Goldin,P.R., \& Gross,J.J.(2010).Effects of mindfulness-based stress reduction (MBSR) on emotion regulation in social anxiety disorder. Emotion, 10(1),83-91. https://doi.org/ 10.1037

Harvey, S. T., Bimler, D., Evans, I. M., Kirkland, J., \&Pechtel, P. (2012). Mapping the class room emotional environment. Teaching and Teacher Education,28, 628-640. https://doi.org/10.1016/j.tate.2012.01.005

Hattie, J. A. C. (2009). Visible learning: A synthesis of 800+ meta-analyses of achievement. Oxford, UK: Routledge.

Jennings,P.A.,\&Greenberg,M.T.(2009).Theprosocialclassroom:Teachersocialand emotionalcompetenceinrelationtostudentandclassroomoutcomes.ReviewofEducational Research, 79, 491-525. https://doi.org/10.3102/0034654308325693

Jensen, H. \&Gøtzsche, K. (2020). Development of the social, emotional, and intercultural learning programme for school staff in A. Kozina (Ed.). Social, emotional, and intercultural competencies for inclusive school environments across Europe: Relationships matter.Hamburg, Germany: Verlag Dr. Kovač.

https://www.verlagdrkovac.de/volltexte/978-3-339-11406

Jensen,E.,Skibsted,E.B.,\&Christensen,M.V.(2015).Educating teachers focusing on the development of reflective and relational competences. Educational Research for Policy and Practice, 14(3),201-212. https://doi.org/10.1007/s10671-015-9185-0

Jones, S. M., Bouffard, S. M., \& Weissbourd, R. (2013). Educator's social and emotional skills vital to learning. Phi Delta Kappan, 94, 62-65.

Juul, J. \& Jensen, H. (2002). Pcedagogisk relationscompetence. Copenhagen, DK: Apostrof,

Kehoe, M., Bourke-Taylor, H., \& Broderick,D.(2017).Developing student social skills using restorative practices: A new framework called H.E.A.R.T. Social Psychology of Education, 21(1), 189-207. https://doi.org/10.1007/s11218-017-9402-1

Kozina, A. (2020). Social, emotional, and intercultural competencies for inclusive school environments across Europe: Relationships matter. Hamburg, Germany: Verlag Dr. Kovač. https://www.verlagdrkovac.de/volltexte/978-3-339-11406-8.htm

Laursen,E.K.(2018).Intentionalresponsiveadultpractices:Supportingkids to not only overcome adversity but to thrive. Lulu Publishing Services.

Laursen,P.F.\&Nielsen,A.M.(2016).Teachers' relational competences: The contribution from teacher education. Solsko Polje, 27(l-2),139-161.

Low,S.,Smolkowski,K.,\&Cook,C.(2016).What constitutes high-quality implementation of SEL programs? A latent class analysis of second steps implementation. Prevention Science, 17(8), 981-991. https://doi.org/10.1007/s11121-016-0670-3

McInerney, M., \& McKlindon, A.(2014).Unlocking the door to learning. Trauma-informed classrooms \& transformational schools. Educational Law Center.

https://www.elc-pa.org/resource/unlocking-the-door-to-learning-trauma-informed-classrooms-andtransformational-schools/

Nordenbo, S. E., Larsen, M. S., Tiftikci, N., Wendt, R. E., \& Østergaard, S. (2008). Larerkompetanserog elevers laring i barnehage og skole: Et systematisk review utført for Kunnskapsdepartementet, Oslo.Copenhagen, DK: Dansk Clearinghouse for Uddannelsesforskning, Danmarks Pædagogiske Universitetsforlag.

Nielsen, B. L. (2020). Implementing HAND in HAND programme for school staff and students in A. Kozina (Ed.).Social, emotional, and intercultural competencies for inclusive school environments across Europe: Relationships matter. Hamburg, Germany: Verlag Dr. Kovač. 
https://www.verlagdrkovac.de/volltexte/978-3-339-11406

Perry,D.L.,\&Daniels,M.L.(2016).Implementingtrauma-informedpracticesintheschool setting: A pilot study. School Mental Health, 8(1),177-188. https://doi.org/ 10.1007/s12310-016-9182-3

Poulou,M.S.(2016).Social and emotional learning and teacher-student relationships: Preschool teachers' and students' perceptions. Early Childhood Education Journal,45(3),427-435. https://doi.org/10.1007/s10643-016-0800-3

Rainbolt, S., Fowler, E. S., \& Mansfield, K. C.(2019).High school teachers' perceptions of restorative discipline practices. NASSP Bulletin,103(2),158-182. https://doi.org/10.1177/0192636519853018

Roorda,D.,Koomen,H.,Spilt,J.,\&Oort,F.(2011).The influence of affective teacher-student relationships on students' school engagement and achievement: A meta-analytic approach. Review of Educational Research, 81(4), 493529. http://www.jstor.org/ stab1e/41408670

Rucinski, C. L.,Brown, J. L., \& Downer, J. T. (2018).Teacher-childrelationships,classroom climate, and children's social-emotional and academic development. Journal of Educational Psychology, 110(7), 992-1004. https://doi.org/10.1037/edu0000240

Schumacher, A. (2014). Talking circles for adolescent girls in an urban high school: A restorative practices program for building friendships and developing emotional literacy skills. SAGE Open, 4(4), 1-13. https://doi.org/10.1177/2158244014554204

Semple,R.J.,Lee,J.,Rosa,D.,\&Miller,L.F.(2010).A randomized trial of mindfulness-based cognitive therapy for children: Promoting mindful attention to enhance social-emotional resiliency in children. Journal of Child and Family Studies, 19(2),218-229. https://doi.org/10.1007/s10826-009-9301-y

Shamblin, S., Graham, D., \& Bianco, J. A. (2016). Creating trauma-informed schools for rural Appalachia: The partnerships program for enhancing resiliency, confidence, and workforce development in early childhood education. School Mental Health, 8(1), 189-200. https://doi.org/10.1007/s12310-016-9181-4

Shonk,S.M.,\&Cicchetti,D.(2001).Maltreatment, competency deficits, and risk for academic and behavioral maladjustment. Developmental Psychology, 37(1),3-17.https://doi.org/ 10.1037/0012-1649.37.1.3

Silverman, J., \& Mee,M.(2018).Using restorative practices to prepare teachers to meet the needs of young adolescents. Education Sciences, 8(3), 131-137. https://doi.org/ 10.3390/educsci8030131

Substance Abuse and Mental Health Services Administration (SAMHSA). (2017).Understanding child trauma. https://www.samhsa.gov/child-trauma/understanding-child-trauma

Valente, S., Monteiro, A. P., \& Lourenço, A. A. (2018). The relationship between teachers' emotional intelligence and classroom discipline management. PsychologyintheSchools, 56(5), 741-750. https://doi.org/10.1002/pits.22218

Vidmar, M. \& Kerman,K.(2016).Thedevelopmentofteacher'srelationalcompetencescale: Structural validity and reliability. Solsko Polje, 27,41-67.

Wachtel,T.(2016).Defining restorative. International Institute for Restorative Practices. https://www.iirp.edu/images/pdf/Defining-Restorative_Nov-2016.pdf

Wu,Y.,Lian,K.,Hong,P.,Liu,S.,Lin,R.,\&Lian,R.(2019).Teachers' emotional intelligence and self-efficacy: Mediating role of teaching performance. Social Behavior and Personality: An International Journal, 47(3),110.https://doi.org/10.2224/sbp.78d9

Zenner,C.,Herrnleben-Kurz,S.,\&Walach,H.(2014).Mindfulness-based interventions in schools-a systematic review and meta-analysis. Frontiers in Psychology,5,1-20. https://doi.org/10.3389/fpsyg.2014.00603 